\title{
Ulam-Hyers Stability Results for Fixed Point Problems via $\alpha-\psi$-Contractive Mapping in (b)-Metric Space
}

\author{
Monica-Felicia Bota, ${ }^{1}$ Erdal Karapınar, ${ }^{2}$ and Oana Mleşniţe ${ }^{1}$ \\ ${ }^{1}$ Department of Mathematics, Babeş-Bolyai University, Kogălniceanu Street No. 1, 400084 Cluj-Napoca, Romania \\ ${ }^{2}$ Department of Mathematics, Atilim University, Incek, 06836 Ankara, Turkey
}

Correspondence should be addressed to Erdal Karapınar; erdalkarapinar@yahoo.com

Received 17 May 2013; Accepted 28 July 2013

Academic Editor: Janusz Brzdek

Copyright ( $(2013$ Monica-Felicia Bota et al. This is an open access article distributed under the Creative Commons Attribution License, which permits unrestricted use, distribution, and reproduction in any medium, provided the original work is properly cited.

We will investigate some existence, uniqueness, and Ulam-Hyers stability results for fixed point problems via $\alpha$ - $\psi$-contractive mapping of type- $(b)$ in the framework of $b$-metric spaces. The presented theorems extend, generalize, and unify several results in the literature, involving the results of Samet et al. (2012).

\section{Introduction and Preliminaries}

Very recently, Samet et al. [1] introduced the notion of $\alpha$ $\psi$-contractive type mapping and proved some fixed point results for such mapping. The authors [1] also reported that several fixed point theorems, including the celebrated Banach contraction mapping principle, can be derived from their main results.

The aim of this manuscript is to investigate the existence and/or uniqueness of a fixed point of $\alpha$ - $\psi$-contractive type mapping in the context of a $b$-metric space, a generalization of a usual metric space, which was introduced by Czerwik $[2,3]$. In fact, such general settings of metric spaces were considered earlier, for example, by Bourbaki [4], Bakhtin [5], and Heinonen [6]. Following these initial papers, $b$-metric spaces and related fixed point theorems have been investigated by a number of authors; see for example, Boriceanu et al. [7], Boriceanu [8, 9], Bota [10], and Aydi et al. [11, 12]. As a subsidiary purpose, we consider Ulam-Hyers stability of the observed results. The stability problem of functional equations, originated from a question of Ulam [13], in 1940, concerns the stability of group homomorphisms. The first affirmative partial answer to the question of Ulam for Banach spaces was given by Hyers [14] in 1941. Thereafter, this type of stability is called the Ulam-Hyers stability and has attracted attention of several authors. In particular, UlamHyers stability results in fixed point theory have been studied densely; see for example, Bota-Boriceanu and Petrușel [15], Lazăr [16], Rus [17, 18], and F. A. Tişe and I. C. Tişe [19]. Moreover, there are several remarkable results on the stability of certain classes of functional equations via fixed point approach. Most particularly and recently, Brzdęk et al. [20], Brzdęk and Ciepliński [21, 22], and Cadariu [23] reported some interesting results in this direction.

We recollect some essential definitions and fundamental results. We first recall the definition of a $b$-metric space.

Definition 1 (Bakhtin [5], Czerwik [2]). Let $X$ be a set, and let $s \geq 1$ be a given real number. A functional $d: X \times$ $X \rightarrow[0, \infty)$ is said to be a $b$-metric space if the following conditions are satisfied:

(1) $d(x, y)=0$ if and only if $x=y$,

(2) $d(x, y)=d(y, x)$,

(3) $d(x, z) \leq s[d(x, y)+d(y, z)]$,

for all $x, y$, and $z \in X$. A pair $(X, d)$ is called a $b$-metric space.

It is clear that $b$-metric turns into usual metric when we take $s=1$. Hence, we conclude that the class of $b$-metric spaces is larger than the class of usual metric spaces. For more details and examples on $b$-metric spaces, see, for example, $[2-6,24]$. We state the following example for the sake of completeness. 
Example 2. Let $X$ be a set with the cardinal $\operatorname{card}(X) \geq 3$. Suppose that $X=X_{1} \cup X_{2}$ is a partition of $X$ such that $\operatorname{card}\left(X_{1}\right) \geq 2$. Let $s>1$ be arbitrary. Then, the functional $d: X \times X \rightarrow[0, \infty)$ defined by

$$
d(x, y):= \begin{cases}0, & x=y \\ 2 s, & x, y \in X_{1} \\ 1, & \text { otherwise }\end{cases}
$$

is a $b$-metric on $X$ with coefficient $s>1$.

Let $(X, d)$ be a $b$-metric space. We consider next the following families of subsets of

$$
\mathscr{P}(X):=\{Y \mid Y \subset X \text { and } Y \neq \emptyset\}
$$

In this case $D$ is a generalized functional on a $b$-metric space $(X, d)$ defined by

$$
\begin{gathered}
D: P(X) \times P(X) \longrightarrow[0, \infty) \cup\{+\infty\} \\
D(A, B)= \begin{cases}\inf \{d(a, b) \mid a \in A, b \in B\}, & A \neq \emptyset \neq B ; \\
0, & A=\emptyset=B ; \\
+\infty, & \text { otherwise }\end{cases}
\end{gathered}
$$

In particular, if $x_{0} \in X$, then $D\left(x_{0}, B\right):=D\left(\left\{x_{0}\right\}, B\right)$.

The following basic lemmas will be useful in the proof of the main results.

Lemma 3 (Czerwik [2]). Let $(X, d)$ be a b-metric space. Then, ones has

$$
D(x, A) \leq s[d(x, y)+D(y, A)], \quad \forall x, y \in X \text { and } A \subset X .
$$

Lemma 4 (Czerwik [2]). Let $(X, d)$ be a b-metric space, and let $\left\{x_{k}\right\}_{k=0}^{n} \subset X$. Then

$$
\begin{aligned}
d\left(x_{n}, x_{0}\right) \leq & s d\left(x_{0}, x_{1}\right)+\cdots+s^{n-1} d\left(x_{n-2}, x_{n-1}\right) \\
& +s^{n-1} d\left(x_{n-1}, x_{n}\right)
\end{aligned}
$$

A mapping $\varphi:[0, \infty) \rightarrow[0, \infty)$ is called a comparison function if it is increasing and $\varphi^{n}(t) \rightarrow 0, n \rightarrow \infty$, for any $t \in$ $[0, \infty)$. We denote by $\Phi$ the class of the comparison function $\varphi:[0, \infty) \rightarrow[0, \infty)$. For more details and examples, see, for example, $[25,26]$. Among them, we recall the following essential result.

Lemma 5 (Berinde [26], Rus [25]). If $\varphi:[0, \infty) \rightarrow[0, \infty)$ is a comparison function, then

(1) each iterate $\varphi^{k}$ of $\varphi, k \geq 1$, is also a comparison function;

(2) $\varphi$ is continuous at 0 ;

(3) $\varphi(t)<t$, for any $t>0$.

Later, Berinde [26] introduced the concept of (c)comparison function in the following way.
Definition 6 (Berinde [26]). A function $\varphi:[0, \infty) \rightarrow[0, \infty)$ is said to be a $(c)$-comparison function if

$\left(c_{1}\right) \varphi$ is increasing,

$\left(c_{2}\right)$ there exist $k_{0} \in \mathbb{N}, a \in(0,1)$, and a convergent series of nonnegative terms $\sum_{k=1}^{\infty} v_{k}$ such that $\varphi^{k+1}(t) \leq$ $a \varphi^{k}(t)+v_{k}$, for $k \geq k_{0}$ and any $t \in[0, \infty)$.

The notion of a (c)-comparison function was improved as a (b)-comparison function by Berinde [27] in order to extend some fixed point results to the class of $b$-metric space.

Definition 7 (Berinde [27]). Let $s \geq 1$ be a real number. A mapping $\varphi:[0, \infty) \rightarrow[0, \infty)$ is called a $(b)$-comparison function if the following conditions are fulfilled:

(1) $\varphi$ is monotonically increasing;

(2) there exist $k_{0} \in \mathbb{N}, a \in(0,1)$, and a convergent series of nonnegative terms $\sum_{k=1}^{\infty} v_{k}$ such that $s^{k+1} \varphi^{k+1}(t) \leq$ $a s^{k} \varphi^{k}(t)+v_{k}$, for $k \geq k_{0}$ and any $t \in[0, \infty)$.

We denote by $\Psi_{b}$ for the class of $(b)$-comparison function $\varphi:[0, \infty) \rightarrow[0, \infty)$. It is evident that the concept of (b)-comparison function reduces to that of $(c)$-comparison function when $s=1$.

The following lemma has a crucial role in the proof of our main result.

Lemma 8 (Berinde [24]). If $\varphi:[0, \infty) \rightarrow[0, \infty)$ is $a(b)$ comparison function, then ones has the following:

(1) the series $\sum_{k=0}^{\infty} s^{k} \varphi^{k}(t)$ converges for any $t \in \mathbb{R}_{+}$;

(2) the function $b_{s}:[0, \infty) \rightarrow[0, \infty)$ defined by $b_{s}(t)=$ $\sum_{k=0}^{\infty} s^{k} \varphi^{k}(t), t \in[0, \infty)$, is increasing and continuous at 0 .

We note that any $(b)$-comparison function is a comparison function due to Lemma 8.

Next, we will present the definition of $\alpha-\psi$-contractive and $\alpha$-admissible mappings introduced by Samet et al. [1]

We denote by $\Psi$ the family of nondecreasing functions $\psi:[0, \infty) \rightarrow[0, \infty)$ such that $\sum_{n=1}^{\infty} \psi^{n}(t)<\infty$ for each $t>0$. It is clear that if $\Psi \subset \Phi$ (see, e.g., [28]) and, hence, by Lemma 5 (14), for $\psi \in \Psi$, we have $\psi(t)<t$, for any $t>0$.

Definition 9 (Samet et al. [1]). Let $(X, d)$ be a metric space and $f: X \rightarrow X$ a given mapping. One says that $f$ is an $\alpha-\psi-$ contractive mapping if there exist two functions $\alpha: X \times X \rightarrow$ $[0, \infty)$ and $\psi \in \Psi$ such that

$$
\alpha(x, y) d(f(x), f(y)) \leq \psi(d(x, y)), \quad \forall x, y \in X .
$$

Remark 10. If $f: X \rightarrow X$ satisfies the Banach contraction principle, then $f$ is an $\alpha-\psi$-contractive mapping, where $\alpha(x, y)=1$ for all $x, y \in X$ and $\psi(t)=k t$ for all $t \geq 0$ and some $k \in[0,1)$.

Definition 11 (Samet et al. [1]). Let $f: X \rightarrow X$ and $\alpha: X \times$ $X \rightarrow[0, \infty)$. One says that $f$ is $\alpha$-admissible if

$$
x, y \in X, \quad \alpha(x, y) \geq 1 \Longrightarrow \alpha(f(x), f(y)) \geq 1 .
$$


Let $\mathscr{F}_{f}(X)$ be the class of fixed points of a self-mapping $f$ defined on a nonempty set $X$; that is, $\mathscr{F}_{f}(X)=\{x \in X$ : $f(x)=x\}$.

Example 12 (Samet et al. [1]). Let $X=(0,+\infty)$. Define $f$ : $X \rightarrow X$ and $\alpha: X \times X \rightarrow[0, \infty)$ by

(1) $f(x)=\ln (x)$, for all $x \in X$, and

$$
\alpha(x, y)= \begin{cases}2, & \text { if } x \geq y \\ 0, & \text { if } x<y\end{cases}
$$

Then $f$ is $\alpha$-admissible.

(2) $f(x)=\sqrt{x}$, for all $x \in X$, and

$$
\alpha(x, y)= \begin{cases}e^{x-y}, & \text { if } x \geq y \\ 0, & \text { if } x<y\end{cases}
$$

Then $f$ is $\alpha$-admissible.

Example 13. Let $(X, \preceq)$ be a partially ordered set and $d$ a metric on $X$ such that $(X, d)$ is complete. Let $T: X \rightarrow X$ be a nondecreasing mapping with respect to $\preceq$; that is, $x, y \in$ $X, x \preceq y \Rightarrow T x \preceq T y$. Suppose that there exists $x_{0} \in X$ such that $x_{0} \preceq T x_{0}$. Define the mapping $\alpha: X \times X \rightarrow[0, \infty)$ by

$$
\alpha(x, y)= \begin{cases}1, & \text { if } x \preceq y \text { or } \quad x \geq y, \\ 0, & \text { otherwise. }\end{cases}
$$

Then, $T$ is $\alpha$-admissible. Since there exists $x_{0} \in X$ such that $x_{0} \preceq T x_{0}$, we have $\alpha\left(x_{0}, T x_{0}\right) \geq 1$. On the other hand, for all $x, y \in X$, from the monotone property of $T$, we have

$$
\begin{aligned}
& \alpha(x, y) \geq 1 \Longrightarrow x \geq y \\
& \text { or } \quad x \leq y \Longrightarrow T x \geq T y \\
& \text { or } \quad T x \leq T y \Longrightarrow \alpha(T x, T y) \geq 1 .
\end{aligned}
$$

Thus $T$ is $\alpha$-admissible.

Theorem 14 (Samet et al. [1]). Let $(X, d)$ be a complete metric space and $f: X \rightarrow X$ an $\alpha-\psi$-contractive mapping satisfying the following conditions:

(i) $f$ is $\alpha$-admissible;

(ii) there exists $x_{0} \in X$ such that $\alpha\left(x_{0}, f\left(x_{0}\right)\right) \geq 1$;

(iii) $f$ is continuous.

Then, $f$ has a fixed point; that is, there exists $x^{*} \in \mathscr{F}_{f}(X)$.

Theorem 15 (Samet et al. [1]). Let $(X, d)$ be a complete metric space and $f: X \rightarrow X$ an $\alpha-\psi$-contractive mapping satisfying the following conditions:

(i) $f$ is $\alpha$-admissible;

(ii) there exists $x_{0} \in X$ such that $\alpha\left(x_{0}, f\left(x_{0}\right)\right) \geq 1$;

(iii) if $\left\{x_{n}\right\}$ is a sequence in $X$ such that $\alpha\left(x_{n}, x_{n+1}\right) \geq 1$ for all $n$ and $x_{n} \rightarrow x \in X$ as $n \rightarrow \infty$, then $\alpha\left(x_{n}, x\right) \geq 1$ for all $n$.

Then, $f$ has a fixed point; that is, there exists $x^{*} \in \mathscr{F}_{f}(X)$.

\section{Main Results}

First we give the following definition as a generalization of Definition 9.

Definition 16. Let $(X, d)$ a $b$-metric space and $f: X \rightarrow X$ be a given mapping. We say that $f$ is an $\alpha$ - $\psi$-contractive mapping of type-(b) if there exist two functions $\alpha: X \times X \rightarrow$ $[0, \infty)$ and $\psi \in \Psi_{b}$ such that

$$
\alpha(x, y) d(f(x), f(y)) \leq \psi(d(x, y)), \quad \forall x, y \in X .
$$

Our first main result is the following.

Theorem 17. Let $(X, d)$ be a complete b-metric space with constant $s>1$. Let $f: X \rightarrow X$ be an $\alpha$ - $\psi$-contractive mapping of type-(b) satisfying the following conditions:

(i) $f$ is $\alpha$-admissible;

(ii) there exists $x_{0} \in X$ such that $\alpha\left(x_{0}, f\left(x_{0}\right)\right) \geq 1$;

(iii) $f$ is continuous.

Then the fixed point equation (29) has a solution; that is, there exists $x^{*} \in \mathscr{F}_{f}(X)$.

Proof. Let $x_{0} \in X$ such that $\alpha\left(x_{0}, f\left(x_{0}\right)\right) \geq 1$ (such a point exists from condition (ii)). Define the sequence $\left\{x_{n}\right\}$ in $X$ by

$$
x_{n+1}=f\left(x_{n}\right), \quad \forall n \in \mathbb{N} \cup\{0\} .
$$

If $x_{n}=x_{n+1}$ for some $n \in \mathbb{N} \cup\{0\}$, then $x^{*}=x_{n}$ is a fixed point for $f$, and the proof finishes. Hence we assume that

$$
x_{n} \neq x_{n+1} \quad \forall n \in \mathbb{N} \cup\{0\} .
$$

Since $f$ is $\alpha$-admissible, we have

$$
\begin{aligned}
\alpha\left(x_{0}, x_{1}\right) & =\alpha\left(x_{0}, f\left(x_{0}\right)\right) \\
& \geq 1 \Longrightarrow \alpha\left(f\left(x_{0}\right), f\left(x_{1}\right)\right) \\
& =\alpha\left(x_{1}, x_{2}\right) \geq 1 .
\end{aligned}
$$

By induction, we get

$$
\alpha\left(x_{n}, x_{n+1}\right) \geq 1, \quad \forall n \in \mathbb{N} \cup\{0\} .
$$

Applying the inequality (12) with $x=x_{n-1}$ and $y=x_{n}$ and using (16), we obtain

$$
\begin{aligned}
d\left(x_{n}, x_{n+1}\right) & =d\left(f\left(x_{n-1}\right), f\left(x_{n}\right)\right) \\
& \leq \alpha\left(x_{n-1}, x_{n}\right) d\left(f\left(x_{n-1}\right), f\left(x_{n}\right)\right) \\
& \leq \psi\left(d\left(x_{n-1}, x_{n}\right)\right) .
\end{aligned}
$$

By induction, we get

$$
d\left(x_{n}, x_{n+1}\right) \leq \psi^{n}\left(d\left(x_{0}, x_{1}\right)\right), \quad \forall n \in \mathbb{N} \cup\{0\} .
$$


From (18) and using the triangular inequality, for all $p \geq 1$, we have

$$
\begin{aligned}
d\left(x_{n}, x_{n+p}\right) \leq & s d\left(x_{n}, x_{n+1}\right)+s^{2} d\left(x_{n+1}, x_{n+2}\right) \\
& +\cdots+s^{p-2} d\left(x_{n+p-3}, x_{n+p-2}\right) \\
& +s^{p-1} d\left(x_{n+p-2}, x_{n+p-1}\right) \\
& +s^{p} d\left(x_{n+p-1}, x_{n+p}\right) \\
\leq & s \psi^{n}\left(d\left(x_{0}, x_{1}\right)\right)+s^{2} \psi^{n+1}\left(d\left(x_{0}, x_{1}\right)\right) \\
& +\cdots+s^{p-2} \psi^{n+p-3}\left(d\left(x_{0}, x_{1}\right)\right) \\
& +s^{p-1} \psi^{n+p-2}\left(d\left(x_{0}, x_{1}\right)\right) \\
& +s^{p-1} \psi^{n+p-1}\left(d\left(x_{0}, x_{1}\right)\right) \\
= & \frac{1}{s^{n-1}}\left[s^{n} \psi^{n}\left(d\left(x_{0}, x_{1}\right)\right)\right. \\
& +s^{n+1} \psi^{n+1}\left(d\left(x_{0}, x_{1}\right)\right) \\
& +\cdots+s^{n+p-2} \psi^{n+p-2}\left(d\left(x_{0}, x_{1}\right)\right) \\
& \left.+s^{n+p-1} \psi^{n+p-1}\left(d\left(x_{0}, x_{1}\right)\right)\right] .
\end{aligned}
$$

Denoting $S_{n}=\sum_{k=0}^{n} s^{k} \psi^{k}\left(d\left(x_{0}, x_{1}\right)\right), n \geq 1$, we obtain

$$
d\left(x_{n}, x_{n+p}\right) \leq \frac{1}{s^{n-1}}\left[S_{n+p-1}-S_{n-1}\right], \quad n \geq 1, p \geq 1 .
$$

Due to the assumption (14) and Lemma 8, we conclude that the series $\sum_{k=0}^{n} s^{k} \psi^{k}\left(d\left(x_{0}, x_{1}\right)\right)$ is convergent. Thus there exists $S=\lim _{n \rightarrow \infty} S_{n} \in[0, \infty)$. Regarding $s \geq 1$ and by (20), we obtain that $\left\{x_{n}\right\}_{n \geq 0}$ is a Cauchy sequence in the $b$-metric space $(X, d)$. Since $(X, d)$ is complete, there exists $x^{*} \in X$ such that $x_{n} \rightarrow x^{*}$ as $n \rightarrow \infty$. From the continuity of $f$, it follows that $x_{n+1}=f\left(x_{n}\right) \rightarrow f\left(x^{*}\right)$ as $n \rightarrow \infty$. By the uniqueness of the limit, we get $x^{*}=f\left(x^{*}\right)$; that is, $x^{*}$ is a fixed point of $f$.

In the following theorem, we are able to omit the continuity hypothesis of $f$ by adding a new condition.

Theorem 18. Let $(X, d)$ be a complete b-metric space with constant $s>1$. Let $f: X \rightarrow X$ be an $\alpha$ - $\psi$-contractive mapping of type-(b) satisfying the following conditions:

(i) $f$ is $\alpha$-admissible;

(ii) there exists $x_{0} \in X$ such that $\alpha\left(x_{0}, f\left(x_{0}\right)\right) \geq 1$;

(iii) if $\left\{x_{n}\right\}$ is a sequence in $X$ such that $\alpha\left(x_{n}, x_{n+1}\right) \geq 1$ for all $n$ and $x_{n} \rightarrow x \in X$ as $n \rightarrow \infty$, then $\alpha\left(x_{n}, x\right) \geq 1$ for all $n$.

Then the fixed point equation (29) has a solution.

Proof. Following the proof of Theorem 17, we know that $\left\{x_{n}\right\}$ is a Cauchy sequence in the complete $b$-metric space $(X, d)$.
Then, there exists $x^{*} \in X$ such that $x_{n} \rightarrow x^{*}$ as $n \rightarrow \infty$. On the other hand, from (16) and the hypothesis (iii), we have

$$
\alpha\left(x_{n}, x^{*}\right) \geq 1, \quad \forall n \in \mathbb{N} .
$$

Now, using the triangular inequalities, (12) and (21), we get

$$
\begin{aligned}
& d\left(f\left(x^{*}\right), x^{*}\right) \\
& \quad \leq s\left[d\left(f\left(x^{*}\right), f\left(x_{n}\right)\right)+d\left(x_{n+1}, x^{*}\right)\right] \\
& \quad \leq s\left[\alpha\left(x_{n}, x^{*}\right) d\left(f\left(x^{*}\right), f\left(x_{n}\right)\right)+d\left(x_{n+1}, x^{*}\right)\right] \\
& \quad \leq s\left[\psi\left(d\left(x_{n}, x^{*}\right)\right)+d\left(x_{n+1}, x^{*}\right)\right] .
\end{aligned}
$$

Letting $n \rightarrow \infty$, since $\psi$ is continuous at $t=0$, we obtain $d\left(f\left(x^{*}\right), x^{*}\right)=0$; that is, $x^{*}=f\left(x^{*}\right)$.

To assure the uniqueness of the fixed point, we will consider the following hypothesis:

$$
\begin{aligned}
& \forall x, y \in X \text {, there exists } z \in X \\
& \text { such that } \alpha(x, z) \geq 1, \quad \alpha(y, z) \geq 1 .
\end{aligned}
$$

Theorem 19. Adding condition $(H)$ to the hypotheses of Theorem 17 (resp., Theorem 18) one obtains uniqueness of the fixed point of $f$.

Proof. Suppose that $x^{*}$ and $y^{*}$ are two fixed points of $f$. From $(H)$, there exists $z \in X$ such that

$$
\alpha\left(x^{*}, z\right) \geq 1, \quad \alpha\left(y^{*}, z\right) \geq 1 .
$$

Since $f$ is $\alpha$-admissible, from (23), we get

$$
\alpha\left(x^{*}, f^{n}(z)\right) \geq 1, \quad \alpha\left(y^{*}, f^{n}(z)\right) \geq 1 .
$$

Using (24) and (12), we have

$$
\begin{aligned}
d\left(x^{*}, f^{n}(z)\right) & =d\left(f\left(x^{*}\right), f\left(f^{n-1}(z)\right)\right) \\
& \leq \alpha\left(x^{*}, f^{n-1}(z)\right) d\left(f\left(x^{*}\right), f\left(f^{n-1}(z)\right)\right) \\
& \leq \psi\left(d\left(x^{*}, f^{n-1}(z)\right)\right)
\end{aligned}
$$

This implies that

$$
d\left(x^{*}, f^{n}(z)\right) \leq \psi^{n}\left(d\left(x^{*}, z\right)\right), \quad \forall n \in \mathbb{N} .
$$

Then, letting $n \rightarrow \infty$, we have

$$
f^{n}(z) \longrightarrow x^{*}
$$

Similarly, using (24) and (12), we get

$$
f^{n}(z) \longrightarrow y^{*} \text { as } n \longrightarrow \infty \text {. }
$$

Using (27) and (28), the uniqueness of the limit gives us $x^{*}=$ $y^{*}$. This finishes the proof.

Remark 20. Theorem 14 (resp., Theorem 15) can be derived from Theorem 17 (resp., Theorem 18) by taking $s=1$. Consequently, all results in [1] can be considered as corollaries of our main results. 


\section{Ulam-Hyers Stability Results through the Fixed Point Problems}

Definition 21. Let $(X, d)$ be a metric space and $f: X \rightarrow X$ an operator. By definition, the fixed point equation

$$
x=f(x)
$$

is called generalized Ulam-Hyers stability if and only if there exists $\psi: \mathbb{R}_{+} \rightarrow \mathbb{R}_{+}$which is increasing, continuous at 0 and $\psi(0)=0$ such that for every $\varepsilon>0$ and for each $w^{*} \in X$ an $\varepsilon$ solution of the fixed point equation (29), that is, $w^{*}$, satisfies the inequality

$$
d\left(w^{*}, f\left(w^{*}\right)\right) \leq \varepsilon .
$$

There exists a solution $x^{*} \in X$ of (29) such that

$$
d\left(w^{*}, x^{*}\right) \leq \psi(\varepsilon)
$$

If there exists $c>0$ such that $\psi(t)=c \cdot t$, for each $t \in \mathbb{R}_{+}$, then the fixed point equation (29) is said to be Ulam-Hyers stability.

For Ulam-Hyers stability results in the case of fixed point problems see Bota-Boriceanu, Petruşel [15], Lazăr [16], and Rus [17, 18].

Regarding the Ulam-Hyers stability problem the ideas given in Petru et al. [29] allow us to obtain the following result.

Theorem 22. Let $(X, d)$ be a complete b-metric space with constant $s>1$. Suppose that all the hypotheses of Theorem 19 hold and additionally that the function $\beta:[0, \infty) \rightarrow[0, \infty)$, $\beta(r):=r-s \psi(r)$ is strictly increasing and onto. Then the following hold.

(a) The fixed point equation (29) is generalized UlamHyers stability.

(b) $\operatorname{Fix}(f)=\left\{x^{*}\right\}$ and if $x_{n} \in X, n \in \mathbb{N}$ are such that $d\left(x_{n}, f\left(x_{n}\right)\right) \rightarrow 0$, as $n \rightarrow \infty$, then $x_{n} \rightarrow x^{*}$, as $n \rightarrow \infty$; that is, the fixed point equation (29) is well posed.

(c) If $g: X \rightarrow X$ is such that there exists $\eta \in[0, \infty)$ with

$$
d(f(x), g(x)) \leq \eta, \quad \forall x \in X
$$

then

$$
y^{*} \in \operatorname{Fix}(g) \Longrightarrow d\left(x^{*}, y^{*}\right) \leq \beta^{-1}(s \cdot \eta) \text {. }
$$

Proof. (a) Since $f: X \rightarrow X$ is a Picard operator, so $\operatorname{Fix}(f)=$ $\left\{x^{*}\right\}$. Let $\varepsilon>0$ and $w^{*} \in X$ be a solution of (30); that is,

$$
d\left(w^{*}, f\left(w^{*}\right)\right) \leq \varepsilon .
$$

Since $f$ is $\alpha$ - $\psi$-contractive mapping of type- $(b)$ and since $x^{*} \epsilon$ $\operatorname{Fix}(f)$, from $(H)$, there exists $w^{*} \in X$ such that $\alpha\left(x^{*}, w^{*}\right) \geq$ 1 ; we obtain

$$
\begin{aligned}
d\left(x^{*}, w^{*}\right) & =d\left(f\left(x^{*}\right), w^{*}\right) \\
& \leq s\left[d\left(f\left(x^{*}\right), f\left(w^{*}\right)\right)+d\left(f\left(w^{*}\right), w^{*}\right)\right] \\
& \leq s\left[\alpha\left(x^{*}, w^{*}\right) d\left(f\left(x^{*}\right), f\left(w^{*}\right)\right)+\varepsilon\right] \\
& \leq s\left[\psi\left(d\left(x^{*}, w^{*}\right)\right)+\varepsilon\right] .
\end{aligned}
$$

Therefore,

$$
\begin{aligned}
\beta\left(d\left(x^{*}, w^{*}\right)\right) & :=d\left(x^{*}, w^{*}\right)-s \psi\left(d\left(x^{*}, w^{*}\right)\right) \\
& \leq s \cdot \varepsilon \Longrightarrow d\left(x^{*}, w^{*}\right) \\
& \leq \beta^{-1}(s \cdot \varepsilon) .
\end{aligned}
$$

Consequently, the fixed point equation (29) is generalized Ulam-Hyers stability.

(b) Since $f$ is $\alpha-\psi$-contractive mapping of type- $(b)$ and since $x^{*} \in \operatorname{Fix}(f)$, from $(H)$, there exists $x_{n} \in X$ such that $\alpha\left(x^{*}, x_{n}\right) \geq 1$; we obtain

$$
\begin{aligned}
d\left(x_{n}, x^{*}\right) & \leq s\left[d\left(x_{n}, f\left(x_{n}\right)\right)+d\left(f\left(x_{n}\right), x^{*}\right)\right] \\
& =s\left[d\left(x_{n}, f\left(x_{n}\right)\right)+d\left(f\left(x_{n}\right), f\left(x^{*}\right)\right)\right] \\
& \leq s\left[d\left(x_{n}, f\left(x_{n}\right)\right)+\alpha\left(x_{n}, x^{*}\right) d\left(f\left(x_{n}\right), f\left(x^{*}\right)\right)\right] \\
& \leq s\left[d\left(x_{n}, f\left(x_{n}\right)\right)+\psi\left(d\left(x_{n}, x^{*}\right)\right)\right] .
\end{aligned}
$$

Therefore

$$
\begin{aligned}
\beta\left(d\left(x_{n}, x^{*}\right)\right) & :=d\left(x_{n}, x^{*}\right)-s \psi\left(d\left(x_{n}, x^{*}\right)\right) \\
& \leq s d\left(x_{n}, f\left(x_{n}\right)\right) \longrightarrow 0 \text { as } n \longrightarrow \infty \\
& \Longrightarrow d\left(x_{n}, x^{*}\right) \longrightarrow 0 \quad \text { as } n \longrightarrow \infty \\
& \Longrightarrow x_{n} \longrightarrow x^{*}, \quad \text { as } n \longrightarrow \infty
\end{aligned}
$$

So, the fixed point equation (29) is well posed.

(c) Since $f$ is $\alpha$ - $\psi$-contractive mapping of type- $(b)$ and since $x^{*} \in \operatorname{Fix}(f)$, from $(H)$, there exists $x \in X$ such that $\alpha\left(x^{*}, x\right) \geq 1$; we obtain

$$
\begin{aligned}
d\left(x, x^{*}\right) & \leq s\left[d(x, f(x))+d\left(f(x), x^{*}\right)\right] \\
& =s\left[d(x, f(x))+d\left(f(x), f\left(x^{*}\right)\right)\right] \\
& \leq s\left[d(x, f(x))+\alpha\left(x, x^{*}\right) d\left(f(x), f\left(x^{*}\right)\right)\right] \\
& \leq s\left[d(x, f(x))+\psi\left(d\left(x, x^{*}\right)\right)\right] .
\end{aligned}
$$

Therefore

$$
\begin{aligned}
\beta\left(d\left(x, x^{*}\right)\right) & :=d\left(x, x^{*}\right)-s \psi\left(d\left(x, x^{*}\right)\right) \\
& \leq s \cdot d(x, f(x)) .
\end{aligned}
$$


So, we have the following estimation:

$$
d\left(x, x^{*}\right) \leq \beta^{-1}(s \cdot d(x, f(x))) .
$$

Writing (41) for $x:=y^{*}$ we get

$$
\begin{aligned}
d\left(x^{*}, y^{*}\right) & \leq \beta^{-1}\left(s \cdot d\left(y^{*}, f\left(y^{*}\right)\right)\right) \\
& =\beta^{-1}\left(s \cdot d\left(s\left(y^{*}\right), f\left(y^{*}\right)\right)\right) \Longrightarrow d\left(x^{*}, y^{*}\right) \\
& \leq \beta^{-1}(s \cdot \eta) .
\end{aligned}
$$

\section{Acknowledgments}

The first author is supported by a grant from the Romanian National Authority for Scientific Research, CNCS UEFISCDI, Project no. PN-II-ID-PCE-2011-3-0094. The last author is supported by the financial support of the Sectoral Operational Programme for Human Resources Development 20072013, cofinanced by the European Social Fund, under the Project no. POSDRU/107/1.5/S/76841 with the title Modern Doctoral Studies: Internationalization and Interdisciplinarity.

\section{References}

[1] B. Samet, C. Vetro, and P. Vetro, "Fixed point theorems for $\alpha-\psi$-contractive type mappings," Nonlinear Analysis. Theory, Methods \& Applications, vol. 75, no. 4, pp. 2154-2165, 2012.

[2] S. Czerwik, "Nonlinear set-valued contraction mappings in b-metric spaces," Atti del Seminario Matematico e Fisico dell'Università di Modena, vol. 46, no. 2, pp. 263-276, 1998.

[3] S. Czerwik, "Contraction mappings in b-metric spaces," Acta Mathematica et Informatica Universitatis Ostraviensis, vol. 1, pp. 5-11, 1993.

[4] N. Bourbaki, Topologie Générale, Herman, Paris, France, 1974.

[5] I. A. Bakhtin, "The contraction mapping principle in quasimetric spaces," Functional Analysis, vol. 30, pp. 26-37, 1989.

[6] J. Heinonen, Lectures on Analysis on Metric Spaces, Springer, New York, NY, USA, 2001.

[7] M. Boriceanu, A. Petruşel, and I. A. Rus, "Fixed point theorems for some multivalued generalized contractions in $b$-metric spaces," International Journal of Mathematics and Statistics, vol. 6, no. 10, pp. 65-76, 2010.

[8] M. Boriceanu, "Strict fixed point theorems for multivalued operators in $b$-metric spaces," International Journal of Modern Mathematics, vol. 4, no. 3, pp. 285-301, 2009.

[9] M. Boriceanu, "Fixed point theory for multivalued generalized contraction on a set with two $b$-metrics," Mathematica, vol. 54, no. 3, pp. 3-14, 2009.

[10] M. Bota, Dynamical Aspects in the Theory of Multivalued Operators, Cluj University Press, 2010.

[11] H. Aydi, M.-F. Bota, E. Karapınar, and S. Mitrović, "A fixed point theorem for set-valued quasi-contractions in b-metric spaces," Fixed Point Theory and Applications, vol. 2012, article 88, 2012.

[12] H. Aydi, M.-F. Bota, E. Karapinar, and S. Moradi, "A common fixed point for weak $\phi$-contractions on $b$-metric spaces," Fixed Point Theory, vol. 13, no. 2, pp. 337-346, 2012.
[13] S. M. Ulam, Problems in Modern Mathematics, John Wiley \& Sons, New York, NY, USA, 1964.

[14] D. H. Hyers, "On the stability of the linear functional equation," Proceedings of the National Academy of Sciences of the United States of America, vol. 27, pp. 222-224, 1941.

[15] M. F. Bota-Boriceanu and A. Petruşel, "Ulam-Hyers stability for operatorial equations," Analele Stiintifice ale Universitatii, vol. 57, no. 1, pp. 65-74, 2011.

[16] V. L. Lazăr, "Ulam-Hyers stability for partial differential inclusions," Electronic Journal of Qualitative Theory of Differential Equations, vol. 21, pp. 1-19, 2012.

[17] I. A. Rus, "The theory of a metrical fixed point theoremml: theoretical and applicative relevances," Fixed Point Theory, vol. 9, no. 2, pp. 541-559, 2008.

[18] I. A. Rus, "Remarks on Ulam stability of the operatorial equations," Fixed Point Theory, vol. 10, no. 2, pp. 305-320, 2009.

[19] F. A. Tişe and I. C. Tişe, "Ulam-Hyers-Rassias stability for set integral equations," Fixed Point Theory, vol. 13, no. 2, pp. 659667, 2012.

[20] J. Brzdęk, J. Chudziak, and Z. Páles, "A fixed point approach to stability of functional equations," Nonlinear Analysis. Theory, Methods \& Applications, vol. 74, no. 17, pp. 6728-6732, 2011.

[21] J. Brzdęk and K. Ciepliński, "A fixed point approach to the stability of functional equations in non-Archimedean metric spaces," Nonlinear Analysis. Theory, Methods \& Applications, vol. 74, no. 18, pp. 6861-6867, 2011.

[22] J. Brzdęk and K. Ciepliński, "A fixed point theorem and the Hyers-Ulam stability in non-Archimedean spaces," Journal of Mathematical Analysis and Applications, vol. 400, no. 1, pp. 6875, 2013.

[23] L. Cadariu, L. Gavruta, and P. Gavruta, "Fixed points and generalized Hyers-Ulam stability," Abstract and Applied Analysis, vol. 2012, Article ID 712743, 10 pages, 2012.

[24] V. Berinde, "Generalized contractions in quasimetric spaces," in Seminar on Fixed Point Theory, vol. 93 of Preprint 3, pp. 3-9, Babeş-Bolyai University, Cluj-Napoca, Romania, 1993.

[25] I. A. Rus, Generalized Contractions and Applications, Cluj University Press, Cluj-Napoca, Romania, 2001.

[26] V. Berinde, Contractii Generalizate şi Aplicatii, vol. 2, Editura Cub Press, Baia Mare, Romania, 1997.

[27] V. Berinde, "Sequences of operators and fixed points in quasimetric spaces," Mathematica, vol. 41, no. 4, pp. 23-27, 1996.

[28] N. Hussain, Z. Kadelburg, S. Radenović, and F. Al-Solamy, "Comparison functions and fixed point results in partial metric spaces," Abstract and Applied Analysis, vol. 2012, Article ID 605781, 15 pages, 2012.

[29] T. P. Petru, A. Petruşel, and J.-C. Yao, "Ulam-Hyers stability for operatorial equations and inclusions via nonself operators," Taiwanese Journal of Mathematics, vol. 15, no. 5, pp. 2195-2212, 2011. 


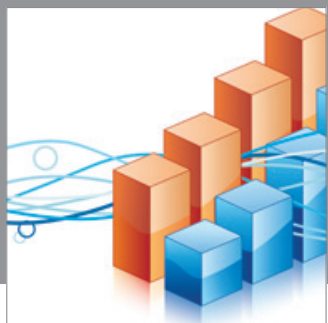

Advances in

Operations Research

mansans

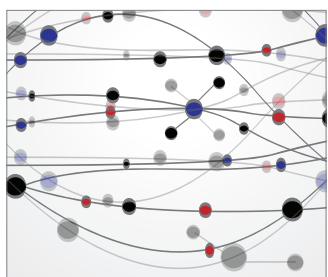

The Scientific World Journal

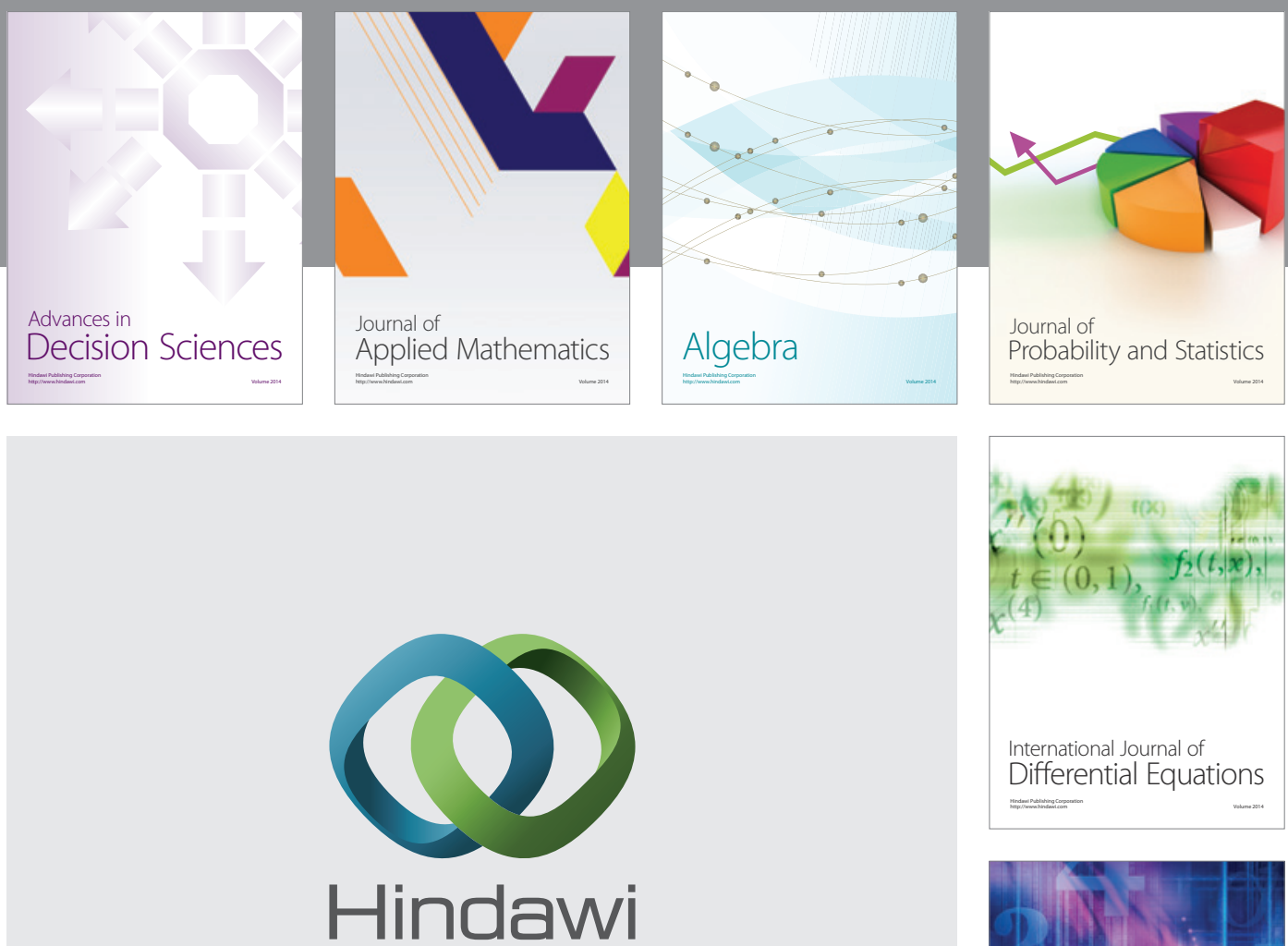

Submit your manuscripts at http://www.hindawi.com
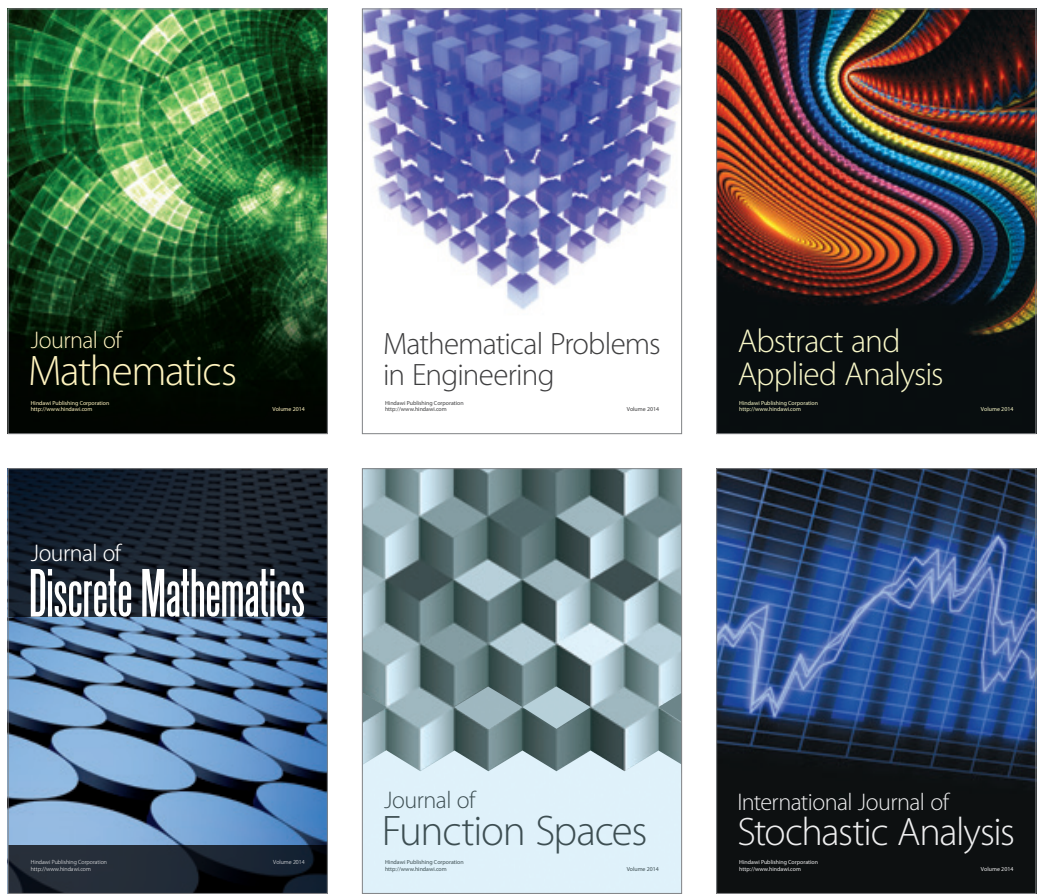

Journal of

Function Spaces

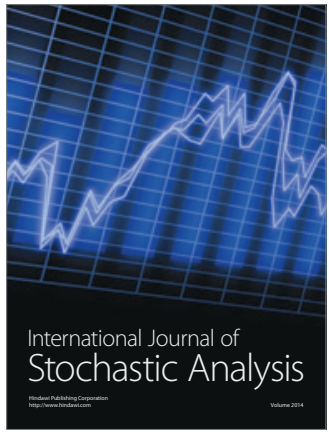

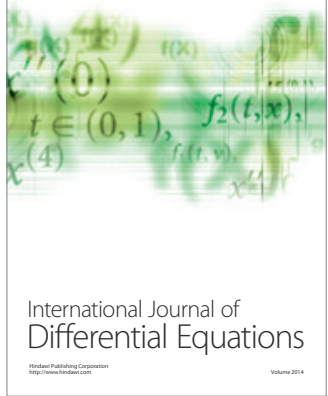
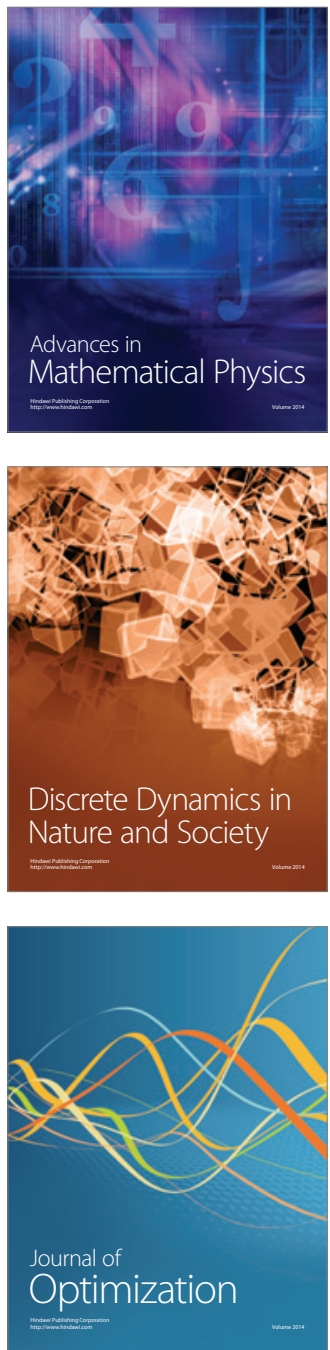